\title{
Appreciation of \\ George Misiewicz - Editor of Gut \\ 1981-1988
}

George Misiewicz has been editor of the journal for seven years while continuing his clinical practice, running a productive research unit, lecturing frequently on the national and international scene and recently serving as President of the British Society of Gastroenterology.

During his tenure the number of papers submitted for review has increased from some 500 to nearly 800 papers annually. He has been responsible for introducing a comprehensive computer based system to record the progress of papers through the editorial system and to ensure ready access to the expertise of the reviewers. The journal has flourished with the introduction of leading articles, editorials, and the correspondence column.

He has made light of this task, revelling in the pleasure of the most organised part of his week thanks to the excellent support of the technical editor, Shirley McGealey and Secretariat, Jackie Foulds and Rhea Haydon. The work has been done with great good humour and a lightness of touch but with a determined commitment to maintain the principle of editorial independence which has been upheld throughout the journal's existence.

In describing the future prospects for the journal in the Jubilee Supplement published last year, he emphasised that the key to continued success was a refusal to compromise with second best and remaining alive to the changing needs and ideas of the British Society of Gastroenterology and the specialty. These were the standards (together with scrupulous fairness to both authors and reviewers) to which he himself worked.

The Society is greatly in his debt for such an outstanding contribution. 